DOI 10.37882/2223-2982.2021.05-2.29

\title{
РЕАЛИЗАЦИЯ ПРИНЦИПА ЛИНГВИСТИЧЕСКОЙ ПАРИТЕТНОСТИ В ШВЕЙЦАРСКОЙ АРМИИ (НА ПРИМЕРЕ ИТАЛЬЯНСКОГО И РЕТОРОМАНСКОГО ЯЗЫКОВ)
}

\section{THE REALIZATION OF THE PARITY PRINCIPLE IN THE SWISS ARMY \\ (ON THE EXAMPLE OF THE ITALIAN AND THE RHAETO-ROMANCE LANGUAGES)}

M. Smirnova

Summary: The article examines the plurilingualism in the Swiss Armed Forces. According to the current Constitution and the provisions of the Army Regulations, the army guarantees linguistic parity for every native speaker among the personnel, but in practice the principle of linguistic parity is only advisory. The focus of the study is based on the Italian and the Rhaeto-Romance languages, which have the lowest representation within the population. The article analyses an initiative taken by the Swiss government to integrate Rhaeto-Romance into the Armed Forces and a field study of the linguistic usage in a military exercise situation.

Keywords: sociolinguistics, languages policy, language legislation, plurilingualism, Italian language, Rhaeto-Romance language.

\author{
Смирнова Мария Александровна \\ К.филол.н., Военный университет \\ Министерства обороны РФ (Москва) \\ fiveoclocktea@gmail.com
}

Аннотация: В статье рассматривается многоязычие в швейцарских вооруженных силах. Согласно действующей Конституции и положениям Воинского устава, армия гарантирует языковое равноправие всем военнослужащим, однако на практике принцип лингвистической паритетности носит лишь рекомендательный характер. В фокусе исследования находятся итальянский и ретороманский языки, имеющие наименьшее представительство среди населения. Анализируется инициатива, предпринятая швейцарским правительством для интеграции ретороманского языка в вооруженные силы, и полевое исследование языкового узуса в ситуации военных учений.

Ключевые слова: социолингвистика, языковая политика, языковое законодательство, многоязычие, итальянский язык, ретороманский язык.
Ш вейцарская Конфедерация - единственное государство в мире, в котором согласно ст. 4 Конституции 1999 г. национальными языками на федеральном уровне признаются 4 языка: немецкий, французский, итальянский и ретороманский. Равенство языков было закреплено в Федеральной конституции 1848 г., а затем в статьях 109 и 116 Конституции 1874 г. и статье 70 Конституции 1999 г. При этом только первые три являются официальными языками, что ограничивает полноту функциональной парадигмы ретороманского языка территорией распространения. Согласно п. 1 ст. 70 ретороманский приобретает официальный статус при взаимодействии государственных институтов с автохтонным населением кантона Граубюнден. П. 2 предусматривает сохранение традиционного языкового состава регионов в целях сохранения лингвистического мира. При этом двуязычный кантон Тичино и трехъязычный кантон Граубюнден имеют право выдвигать собственные инициативы, направленные на поддержание и продвижение итальянского и ретороманского языков (п. 5) [1].

Кантоны Тичино и Граубюнден вместе образуют так называемую Итальянскую Швейцарию (Svizzera italiana). Согласно данным Федерального агентства по статистике (Ufficio Federale di Statistica, UFS), на конец 2020 г. количество италоязычного коренного населения (или имею- щего статус резидента на протяжении периода более 15 лет) составляет 642 тысячи человек, или 8\% [2].

Ретороманский представлен пятью вариантам, на основе которых по заказу Ретороманский лиги (Lia Rumantscha) в 1989 г. швейцарским лингвистом Г. Шмидтом был образован «единый» ретороманский язык-крыша романч грижун (Rumantsch Grischun). Романч грижун имеет преимущественно письменную форму бытования, что не способствует его повсеместной интеграции в сферу повседневного общения. Носители ретороманского языка считаются «абсолютным меньшинством», поскольку на государственном уровне число носителей достигает всего 0,5\% населения. Как пишет Г.М. Горенко, «уникальность языкового богатства декларируется, но на деле основные усилия оказываются направлены лишь на поддержку равноправного функционирования трех официальных языков» [3, с. 100].

Таким образом, швейцарская языковая политика в области миноритарных языков базируется на принципах лингвистической паритетности, свободы языкового выбора и, в случае ретороманского языка, территориальности, что вынужденно противопоставляет государственное и местное законодательство и приводит к дискриминации малых языков [4]. 
Особый интерес в связи с этим представляет реализация принципа паритетности в государственных структурах, в частности, в вооруженных силах, которые должны быть наиболее подверженными нормированию и регламентации с точки зрения языкового узуса.

B XXI в. швейцарская армия начинает принимать все большее участие в международном военном сотрудничестве, что ставит перед ее командованием новые задачи, в том числе в рамках лингвистического обеспечения. Ключевым словом становится «взаимодействие» (interoperabilità), что выводит на первый план английский язык в качестве языка-макропосредника. Вдобавок к этому важную роль играет интеграция военнослужащих, для которых родным не является ни один из национальных языков Швейцарии (по данным UFS - около 5,6\% населения), однако этот вопрос на данный момент не входит в ряд приоритетных.

После Второй мировой войны появляется идеологема так называемой «духовной обороны государства» (Geistige Landesverteidigung), которая должна способствовать национальной когезии и мирному сосуществованию различных языковых групп. Как отмечает Б. Альтерматт, дискурс вокруг лингвистического равноправия в армии сильно мифологизирован, однако на практике его принципы актуализированы довольно слабо [5]. Высший командный состав в языковом отношении представлен в соответствии с пропорциональным принципом, однако на низших иерархических ступенях пропорциональность не соблюдается.

C 1832 г. военная присяга приносится на французском и итальянском языках, тем не менее в течение продолжительного периода во франкоязычных и италоязычных подразделениях немецкий остается единственным языком командования (например, в пехотных и артиллерийских полках кантона Тичино до 1875 г.) [6]. Но и после этого итальянский язык полностью не вошел в армейский обиход. Одна из причин незавершенности процесса - необходимость перевода технической документации, для которой не было выработано соответствующей терминологии.

Вплоть до 1999 г. согласно Конституции (ст. 21, п. 1) действовал территориально-милиционный принцип призыва, формировавший общевойсковые соединения только в рамках одного кантона, что не способствовало многоязычию в армии. После переходного периода и всенародного голосования с 1 января 2004 г. вступила в действие так называемая реформа «Армия XXI», в результате чего было образовано 4 территориальных региона (сегодня - дивизии). Сама организационно-штатная структура швейцарской армии также была реформирована и приближена к НАТОвским стандартам, а численность военнослужащих сокращена с 360 до 120 тысяч. Благодаря все большей специализации подразделений, а также усилению мобильности лингвистическая гомогенность постепенно стала уступать место языковому смешению.

В Воинском уставе 1994 г. сформулированы следующие положения' [7]:

Ст. 2. Принципы. Во соответствии со Ст. 2 Конституции Швейцарская Конфедерация соблюдает свободы и права Народа и стоит на страже независимости и безопасности Государства. Она непрерывно действует в интересах всеобщего процветания, внутренней сплоченности и культурной многогранности Государства. Конфедерация старается в меру возможности обеспечить равные возможности для граждан.

Ст. 54. Язык. Старшие по должности офицеры должны изъясняться, насколько это возможно, на родном языке своих подчиненных. В многоязычных подразделениях офицеры обязаны говорить на литературном языке.

Ст. 77 Воинский долг. Каждый военнослужащий обязан соблюдать права человека и уважать человеческое достоинство, учитывая разнообразие и не допуская дискриминации. Никто не должен становиться объектом предрассудков по причине пола, национальной или этнической принадлежности, языка, возраста, религии, сексуальной ориентации, политических или иных взглядов, социального происхождения, образа жизни или инвалидности.

Ст. 83. Братство. Сотрудничество военнослужащих основано на духе братства. Военнослужащие уважают личность и собственность других военнослужащих и помогают друг другу в случае возникновения необходимости или опасности. Дух братства не зависит от воинское звания, политических и религиозных убеждений, возраста, пола, языка, происхождения или цвета кожи.

Как видно из приведенных примеров, Воинским уставом постулируется возможность многоязычия, однако она соотносится не с потребностями подчиненных военнослужащих, а с лингвистической компетенцией старшего по должности офицера, и тем самым носит рекомендательный характер.

Наиболее показательной в этом отношении является территориальная дивизия № 3 (центральная и юго-восточная Швейцария), в которую входят немецкоязычные кантоны Ури и Швиц, италоязычные Тичино и Граубюн-

\footnotetext{
1 Здесь и далее перевод авторский - М.C.
} 
ден, одновременно единственный трехъязычный кантон Швейцарии, где проживает ретороманское меньшинство.

Как уже упоминалось ранее, ретороманский полностью исключен с языковой точки зрения из лингвистического представительства в армии. В 80-90х гг. XX в. предпринимались попытки ввести ретороманский в армейский обиход, в частности, в рамках этой кампании в 1981 г. был опубликован перевод Воинского устава. Точнее, два перевода, поскольку наддиалектальная письменная форма руманч грижун начала функционировать только с 1983 г.: один для верхнеэнгадинских вариантов (сурсильванского, сутсильванского, сурмиранского и путера) - Reglamaint da servezzan, и второй для нижнеэнгадинского варианта (валладера) - Reglement da survetsch [8].

В год празднования 2000-летия Реторомании (1985 г.) начальник военного управления Граубюндена Р. Менджарди и бригадный генерал Р. Кайохен обратились к Федеральному совету с просьбой образовать ретороманские подразделения. В результате в 1988 г. был сформирован ретороманский 91 горный пехотный батальон, просуществовавший до 1992 г. Несмотря на положительную общественную реакцию, после начала реформы «Армия 95» эксперимент было решено не возобновлять, в первую очередь по причине лингвистической необеспеченности и невозможности перевести техническую документацию [9].

В сравнении с ретороманским, итальянский язык лучше представлен в швейцарской армии, что связано как с существованием предшествующей традиции, так и значительно большим числом носителей. Сайт швейцарских вооруженных сил, структурно относящихся к Департаменту обороны, чрезвычайных ситуаций и спорта, доступен пользователю на четырех языках, в числе которых, однако, не ретороманский, а английский [10].

В 2002 г. Г. Крайз и Ж. Люди из университета Базеля провели полевое исследование, в рамках которого методом включенного наблюдения анализировали военные учения под кодовым названием «Бригада Монтана» на территории современной 3 территориальной дивизии [11].

Из 50 офицеров, принимавших участие в учениях, половина указала в качестве родного языка немецкий, вторая половина - итальянский, присутствовало несколько франкофонов и один ретороманец. Анализ записи их переговоров показал, что языковое переключение в спонтанном общении (то есть вне момента приказа или команды) следует исключительно прагматическому принципу. Так, начальника штаба (итальянского происхождения) продемонстрировал виртуозные способности к адаптации в зависимости от языковой личности собеседника, в то время как его подчиненные предпочитали литературный немецкий язык (Hochdeutsch) для рабочего и повседневного общения, в том числе и италоязычные. В свою очередь, немецкие швейцарцы чаще переходили на местный диалект. Таким образом, эксперимент продемонстрировал различные ожидания и лингвистические компетенции с зависимости от го-

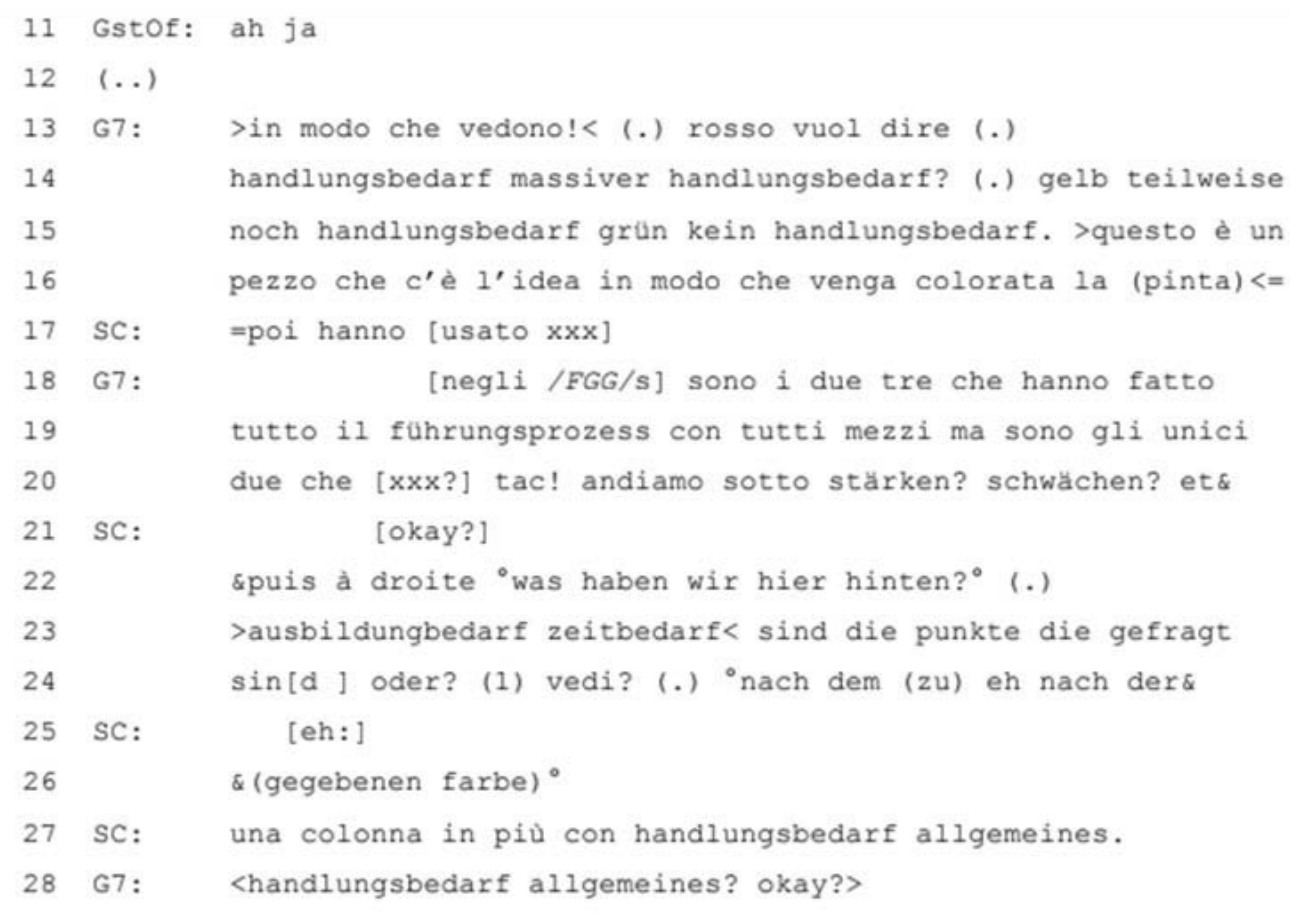

Рис. 1. Расшифровка инструкторско-методического занятия [11, S. 23] 
ризонтального или вертикального типа коммуникации. Ниже приведен пример переключения и смешения кодов в достаточно формализованной ситуации:

В примере расшифровки инструкторско-методического занятия принимают участие SC - начальник генерального штаба, G7 - начальник 7 отдела, отвечающего за образование (уроженец кантона Тичино) и GstOf, офицер генерального штаба (франкофон).

Обращает на себя внимание использование итальянского языка в качестве языка-связки (рекурсия vedi?), в то время как терминология употребляется полностью на немецком языке, несмотря на романское происхождение всех троих офицеров. Мы видим, что итальянский язык обеспечивает когезию текста, за исключением строчки 22 - франц. puis à droite, за которой следует автокоррекция на немецком языке was haben wir hinten с заменой дейктического элемента «справа» на «сзади». При этом немецкие термины интегрируются в неадаптированной форме с сохранением исходных рода и числа (tutto il Führungsprozess), а коды смешиваются: andiamo sotto stärken? (20), Führungsprozess con tutti i mezzi (19), una colonna in più con Handlungsbedarf allgemeines (27).

Авторы отмечают, что лингвистическая компетенция италоязычных военнослужащих 3 территориальной дивизии в целом выше, чем у представителей двух других мажоритарных национальных языков, что связано как с необходимостью ведения повседневной коммуникации, так и тем фактом, что боевые документы преимущественно написаны на немецком языке. Таким образом, немецкий в швейцарских вооруженных силах берет на себя роль не только профессионального языка/субкода, но и профессионального жаргона. По мнению начальника штаба описанных выше учений выбор «доминирующего языка» является служебной необходимостью для достижения цели взаимопонимания, и потому представители меньшинств должны умерить свои притязания на лингвистическую представленность в вооруженных силах [11, S. 19].

В заключение отметим, что развитие многоязычия в швейцарской армии зависит от многих факторов, в частности, от облигаторности изучения национальных языков в школе. Ж. Люди утверждает, что существует четкая взаимозависимость между языковой компетенцией и приоритетом национальных языков в школьной программе над английским языком, который часто рассматривается в качестве компенсаторного при слабом владении остальными государственными языками [12]. При этом принцип лингвистической паритетности в вооруженных силах может носить исключительно рекомендательный характер в силу отсутствия традиции перевода на миноритарные языки военной терминологии. И если в отношении итальянского языка Швейцария в качестве лингвистического образца может опереться на армию Италии, то ретороманский язык полностью лишен на современном этапе представительства. Однако итало-швейцарский военный язык выбрал путь обособления от итальянской модели, что с одной стороны, способствует сохранению этнокультурной специфики, а с другой, требует создания актуальной терминосистемы, которая отражала бы национальные военные реалии и при этом была эффективной в использовании. Это подразумевает, в том числе, наличие службы военных переводчиков для лингвистического обеспечения вооруженных сил Швейцарии.

\section{ЛИТЕРАТУРА}

1. Costituzione federale della Confederazione Svizzera del 18 aprile 1999 [Электронный ресурc]. URL: https://www.admin.ch/opc/it/classifiedcompilation/19995395/index.html\#а4 (дата обращения: 01.03.2021).

2. Ufficio Federale di Statistica [Электронный ресурc]. URL: https://www.bfs.admin.ch/bfs/it/home/statistiche/popolazione/lingue-religioni.html (дата 0бращения: 06.03.2021).

3. Горенко Г.М. К вопросу об истории отечественной ретороманистики // Романские языки и культуры: от античности до современности. 2016. С. 100-104.

4. Родина Л.И. Языковые контакты в условиях многоязычия Швейцарской Конфедерации // Научные ведомости. Серия Гуманитарные науки. 2016. (228). Вып. 29. С. 71-74.

5. Altermatt B. Der Umgang der Schweizer Armee mit der Mehrsprachigkeit: Poportionalität und Territorialität: Ein historischer Überblick mit Standortbestimmung // Schriftenreihe der Eidengenössischen Militärbibliothek EMB und des Historischen Dienstes. Bd. 15. Bern: EMB, 2004 - 92 S.

6. Münger K. Militär, Staat und Nation in der Schweiz 1798-1874: das eidgenössische Militärwesen als Faktor der nationalen Integration von der Helvetischen Republik bis zur Gesamtrevision der Bundesverfassung. Münster: Agenda Verlag, 2002 - 504 S.

7. Regolamento di servizio dell'esercito [Электронный ресурc]. URL: https://www.fedlex.admin.ch/eli/cc/1995/170_170_170/it (дата 0бращения: 06.03.2021).

8. Cumpagnia attent! - Cumpagnia paus! - Far militar par rumantsch [Электронный ресурc]. URL: https://www.rtr.ch/archiv/archivar-recumonda/cumpagniaattent-cumpagnia-paus-far-militar-per-rumantsch (дата обращения: 10.03.2021).

9. Palaia A. Cumpagnia adatg! Das Rätoromanische in der Armee. Bern: EMB, 2009-92 S.

10. II Dipartimento federale della difesa, della protezione della popolazione e dello sport [Электронный pecypc]. URL: https://www.admin.ch/gov/it/pagina-iniziale/ dipartimenti/dipartimento-difesa-protezione-popolazione-sport-ddps.html (дата обращения: 10.03.2021). 
11. Kreis G., Lüdi G. Sprachgebrauch und Umgang mit Mehrsprachigkeit in der Schweizer Armee (am Beispiel einer mehrsprachigen Brigade). Schlussbericht. BaselFreiburg, $2009-33 \mathrm{~S}$.

12. Lüdi G. The Swiss model of plurilingualism // Ten Thije J.D., Zeevart L. Receptive Multilingualism. Linguistic analyses, language policies and didactic concepts. Amsterdam-Philadelphia: John Benjamins, 2007. P. 159-178.

( С Смирнова Мария Александровна (fiveoclocktea@gmail.com).

Журнал «Современная наука: актуальные проблемы теории и практики»

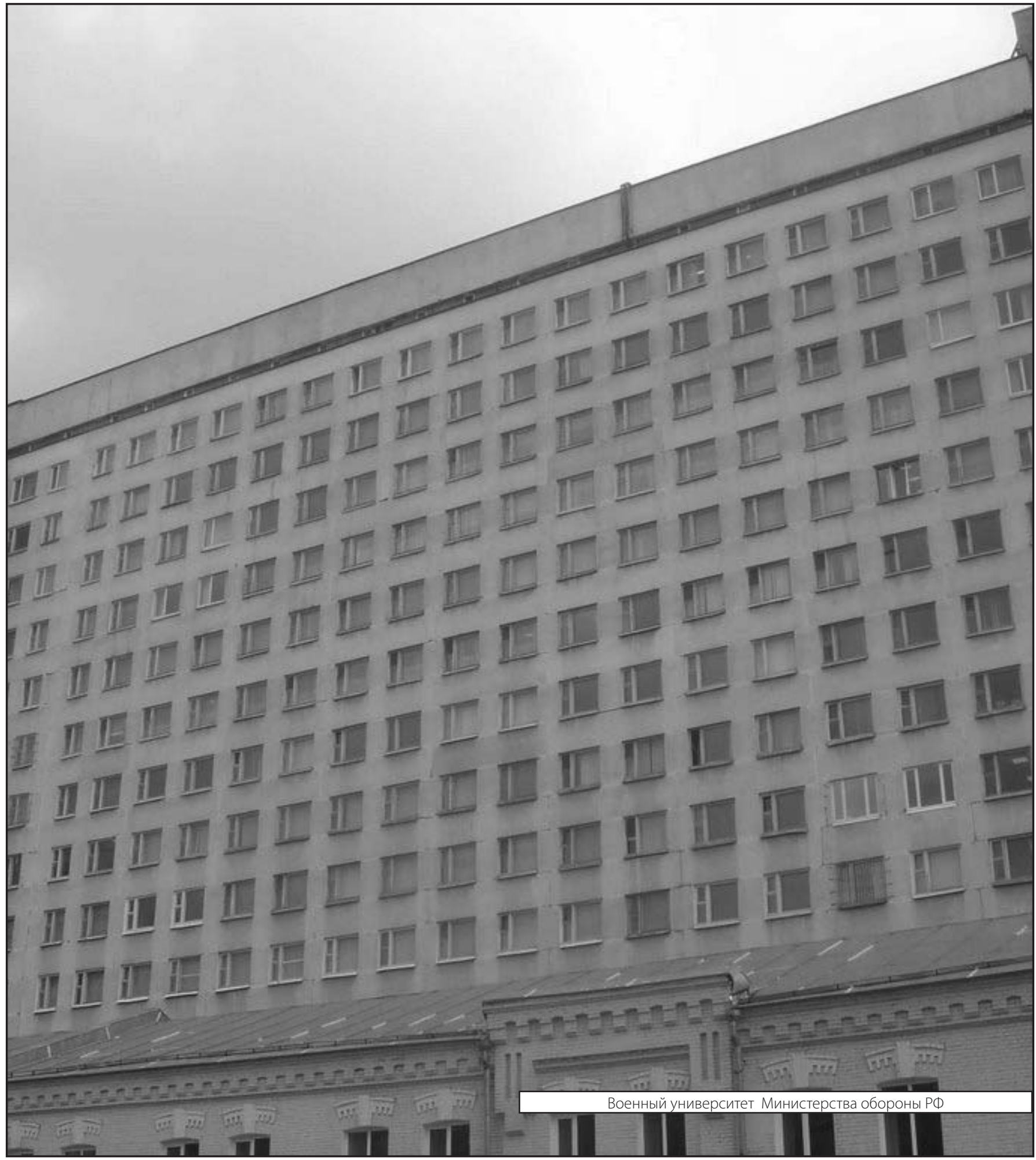

